\title{
Assessing United States and Chinese Secondary Mathematics Teachers' Interest in Fractal Geometry
}

\author{
Suanrong Chen \\ Yangzhou University \\ Sherry Herron \\ Jiu Ding \\ Richard Mohn
}

The University of Southern Mississippi

The purpose of this study was to build the knowledge of secondary math teachers' (referring to grades 6-12 in this study) interest levels for professional development in fractal geometry and look for factors that influence such interests. The instrument of the study included a survey with two parts: demographic information and levels of interest. The results of the study indicated that secondary math teachers in the U.S. and China showed overall moderate levels of interest in learning and teaching fractal knowledge. U.S. teachers showed more interest in each item of fractal learning and teaching than Chinese teachers. Furthermore, the results also indicated that factors such as nationality, age, and experience of integrating fractals made statistically significant differences in teachers' interests. The conclusion leads to some interesting discussions about the differences between U.S. and Chinese educational cultures and systems, as well as some suggestions of which group of teachers to involve in professional development about fractal geometry based on influence levels factors.

Keywords: fractal geometry, secondary mathematics teachers, fractal learning and teaching, interest level

Fractal geometry has become well established as a new subject in mathematics since Benoit Mandelbrot (1977) first introduced it about three decades ago (Vacc, 1999). It has gained great attention from mathematicians and scientists because of its usefulness and wide-ranging applications in many fields such as art, astronomy, nature, computer science, fluid mechanics, etc. (Fraboni \& Moller, 2008). In the field of education, fractal geometry connects many mathematical concepts in school mathematics core curriculum to other subject areas. In cross-curriculum, fractals have been connected to courses such as music, painting, physics, chemistry, and other disciplines. For example, Padula $(2005,2009)$ illustrated how music teachers teach fractal geometry with music. Moreover, the development of technological tools provides more 
possibilities of exploring the dynamics of geometry and displaying the beauty of fractal art. Most importantly, fractal geometry changes the view and the way students think about geometry and explain many natural phenomena that Euclidean geometry cannot explain (Fraboni \& Moller, 2008).

Research has shown that some mathematics educators and teachers have explored how fractal geometry can be integrated into students' math learning even at the elementary level (Adams \& Russ, 1992; Fraboni \& Moller, 2008; Vacc, 1999). However, the treasure of fractal geometry still has not been widely recognized or discovered in secondary mathematics education. This can be demonstrated by the following two facts. First, fractal geometry is not specifically incorporated into the Common Core State Standards for Mathematics (CCSSM) (2015) in the United States or in many other countries, such as Singapore Mathematics Curriculum Standards (2006), Korea Mathematics Curriculum Standards (n.d.), and England Mathematics Curriculum Standards (2014). In China, fractal knowledge is recommended only as an optional topic to be taught rather than required content for entrance exams to universities in math curriculum (China Mathematics Curriculum Standards [CMCS] 10-12, 2003). Second, since most math teachers have not been offered courses related to fractals during their educational learning experiences, they may not know its value and may lack the ability to integrate fractal geometry into the math curriculum.

Thus, most secondary mathematics teachers may not have much experience in: 1) exploring how the math core curriculum supports teaching fractal geometry at the secondary school level; 2) exploring how fractal geometry, as a supplementary material, influences the way students learn and think about geometry; 3) exploring how fractal geometry supports teaching mathematics from the basic concepts to the most advanced concepts; 4) exploring how fractal geometry supports learning across disciplines; and 5) exploring how fractal geometry inspires students' motivation, interest, and curiosity in learning mathematics. However, scattered fractal problems can be found in school math textbooks both in the U.S. and in China, which means mathematics teachers need to build their knowledge of fractals to be fully qualified to teach these contents. This leads researchers to ask the following questions: Are school mathematics teachers interested in learning fractal knowledge and integrating it into their teaching? What factors influence their interest level and how? It is worth getting the answers for teacher trainers to conduct professional development programs about fractal geometry. Further, the differences of interest level in learning and teaching fractals between U.S. and Chinese mathematics teachers provide some insight into the two educational systems.

\section{Theoretical Framework}

Since Benoit Mandelbrot first coined the word "fractal" in 1975 to 
describe shapes that are detailed at all scales (McHugh, 2006), mathematics educators became interested in this field. Although fractal geometry is a relatively new teaching and learning field and was first explored as a learning course starting at the college level, in recent years it has gained some attention in K-12 math education. The exploration of fractal geometry in the classroom now ranges from kindergarten to graduate school (Gluchoff, 2006). Research on fractal geometry in K-12 mostly focuses on how some concrete fractal examples are modified to develop teaching and learning activities based on the grade level of the students, and it is associated with some discussions about the appropriateness and usefulness of creating these activities (e.g., Barton 2003; Fraboni \& Moller 2008; Jarry-Shore 2013; McHugh 2006; Vacc 1999). There are very few studies, which focus on the theoretical discussions about incorporating fractal geometry in math curricula (Davis \& Sumara, 2000). Since fractal geometry is a new mathematical teaching and learning area, research topics in this area still need to be developed on both practical and theoretical levels.

\section{Research on Fractal Teaching Practice}

On a practical level, the existing studies have made contributions to the incorporation of some certain fractal content knowledge in K-12 math curricula and the creation of the corresponding exploratory learning activities for developing students' mathematical thinking and conceptual understanding. Many examples can support this point. Vacc (1999) demonstrated the awareness of possible applications of fractal geometry with children and the appropriateness of including this new mathematics in elementary curricula by creating activities for children to explore basic concepts of fractal geometry. In the study by McHugh (2006), a unit of teaching fractals was incorporated into a geometry course, in which the Sierpinski Triangle and the Cantor Set were chosen as learning materials for third and fourth grade students. McHugh (2006) illustrated how elementary students were exposed to the vocabulary of working with fractals and how they learned to create fractals through hands-on activities and were encouraged to come up with new thoughts about the order and chaos in nature. Fraboni and Moller (2008) presented an example of how iteration, the main tool for creating a fractal, is used to construct fractals and look for patterns associated with the numbers and the areas at each stage of the generated fractals. Jarry-Shore (2013) discussed how an integrated project involving fractals helped students understand several mathematics concepts and create fractal art. Barton (2003) studied how Pascal's Triangle can provide another opportunity to connect young children to deeper mathematical truth; the numeric form of Pascal's Triangle is filled with hidden relationships and connections to deeper mathematics concepts. Singer and Voica (2013) applied fractals in their study to develop a reference framework for designing problem-posing tasks. On the college level, Ding and Li (2009) studied the dimension of Sierpiński pedal triangle, which could be used by college students for practicing calculus 
knowledge. Researchers observed Ding's talk to in-service teachers in a professional development about fractals; the audience was very excited and active in response to the beauty and complexity of fractals. Habecker and Crannell (2004) introduced how fractals and the iterated function system were used to motivate some of the foundational concepts of linear algebra. Barry (2013) conducted the content integration involving fractals for pre-service teachers' interdisciplinary learning. In these cases, inquiry-based learning was the common method utilized in the project study involving fractals and fascinated students.

These studies opened the door of how mathematics educators can integrate fractal geometry in K-12 math curriculum, as well as for college learning. However, they only form the tip of the iceberg for fractal geometry studies. The topics that have been studied only touched a small part of materials and resources of fractal geometry, some basic concepts, terminology and some classical fractal structures; the topics that have been studied only connected to a few points from the other K-12 math content. Thus, the connections between fractal geometry and other K-12 math content needs more empirical development, the appropriateness of fractal geometry at different levels of K12 needs more empirical examination, and the assessment of teaching and learning fractal geometry needs more empirical guidance.

\section{Research on Fractal Teaching Theories}

On a theoretical level, the existing studies have made contributions to illustrate why fractal geometry needs to be incorporated in math curricula, and how fractal geometry can complement and inform other emergent sensibilities in the curricula. For example, Davis and Sumara (2000) gave a deeper discussion and analysis about the limitations of classical geometry for describing the shape and character of natural objects and the emergent changes of fractal geometry for solving problems that classical geometry is unable to do. Davis and Sumara (2000) also gave an examination of the associated notions of fractal geometry for rethinking curriculum and schooling. The International Commission on Mathematical Instruction (ICMI) (1995) argued that the teaching of geometry must reflect the actual and potential needs of society and proposed the question "would it be possible and advisable also to include some elements of non-Euclidean geometries into curricula?" (p. 96). However, along with the needs for practice on fractal geometry, the theory of teaching and learning fractal geometry needs to be developed in many aspects. Many questions need to be answered. What is the domain of teaching and learning fractal geometry in K-12 math curricula? How can this domain be consistently incorporated into each math grade level? What pedagogical knowledge should teachers have in order to integrate fractal geometry into class teaching? What should be changed in current curricula and textbooks for geometry courses? How do we assess the curricula, textbook, workbook, and the effectiveness of teaching and learning within the scope of fractal geometry? What is the role of 
technology in teaching and learning fractal geometry?

Although fractal geometry has received widespread attention in recent years, teaching and learning fractal geometry in the classroom is not universal in the U.S. and China. Only those teachers who are interested in and willing to make changes in geometry teaching put their efforts into integrating fractal geometry into the math curricula. If the theory of teaching and learning fractal geometry can be more available to guide math teachers and educators in practice, the time of universally integrating fractal geometry into the classroom would seem less far away. On the other hand, one of the primary concerns needed to be addressed currently is to provide an important reference to teacher educators about the current state of secondary mathematics teachers' interest in fractal geometry, because when we offer the professional development program about fractals to math teachers we should know which group of teachers to target and how much they are interested in fractal geometry.

\section{State of Problem}

The literature on fractal geometry has demonstrated its value in teaching and learning mathematics at the secondary level (Jarry-Shore, 2013). Chinese National Curriculum Standards have incorporated fractal topics as optional learning contents (CMCS 10-12, 2003). Some U.S. college and secondary mathematics educators have begun to integrate fractal geometry into the math core curriculum (Adams \& Russ, 1992; Fraboni \& Moller, 2008; Vacc, 1999). Incorporating fractal geometry in secondary teaching is gaining certain attention from both countries. However, math teachers lack opportunities to build their knowledge of fractals. Teacher trainers do not pay much attention to this professional development field on the secondary school level. Further, teacher trainers do not know the state of teachers' interest in fractals because no investigation has been done on teachers' interest in learning fractal knowledge and integrating fractal geometry into the secondary core mathematics curriculum. There is a need for providing information to teacher educators on how professional programs about fractals should be organized and carried out for teachers. The purpose of this study is to gain knowledge and information about secondary mathematics teachers' level of interest in learning and teaching fractals in their class and which factors influence such interest and to what extent.

\section{Research Question and Hypothesis}

Research question: Which factors (nationality, gender, age, degree, the years of teaching math, grade levels, experience of learning fractals, and experience of integrating fractals) contribute most and to what extent to teachers' interest levels in integrating fractal geometry in the math core curriculum?

Ha: The factors degree, grade levels, experience of learning fractals, and experience of integrating fractals will account for more variance than gender, age, the years of teaching math, and nationality in the overall mean interest in 
integrating fractal geometry in the math core curriculum.

\section{Framework for Constructing the Survey}

The framework used in the study to construct teachers' interest items in learning and teaching fractal geometry was based on the domains of mathematical knowledge for teaching proposed by Ball, Thames, and Phelps (2008), which includes two subdomains: pedagogical content knowledge (PCK) and subject matter knowledge (SMK). PCK refers to the content knowledge dealing with the teaching process and running the learning activities; SMK refers to the knowledge that deals with common mathematical knowledge of math, special mathematical knowledge of teaching math, and interrelationship of mathematical knowledge in the curriculum (Ball et al., 2008; Shulman, 1986). Each subdomain was further categorized into three types of knowledge, which is detailed in Figure 1.

SUBJECT MATTER KNOWLEDGE

PEDAGOGICAL CONTENT KNOWLEDGE

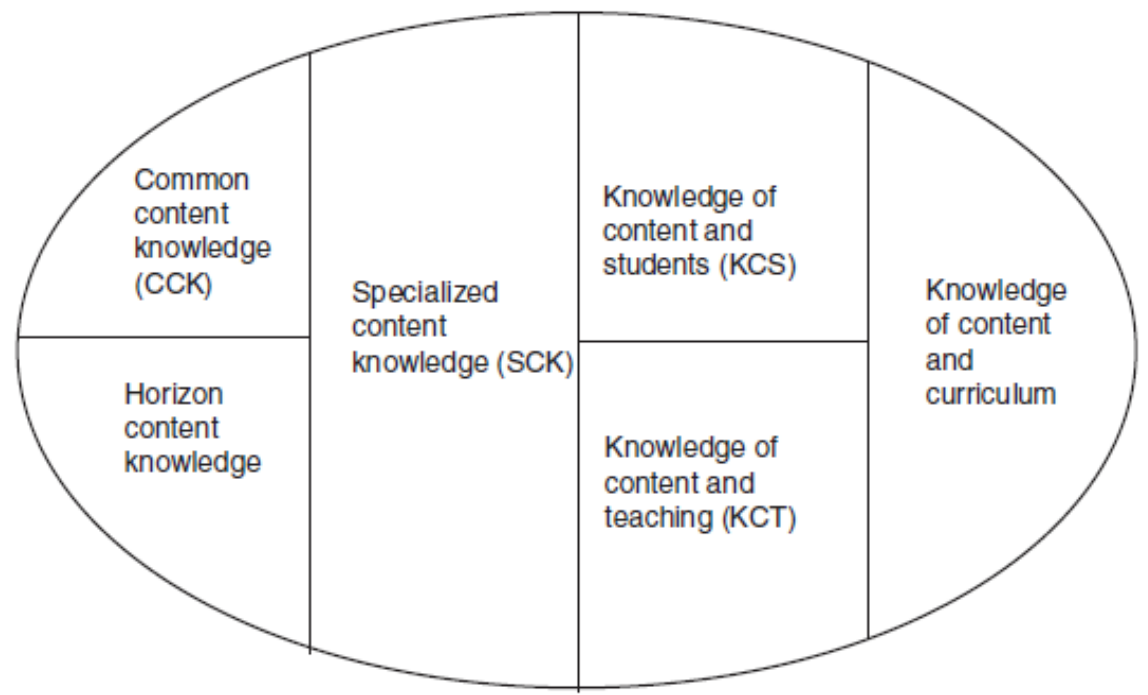

Figure 1. Domains of mathematical knowledge for teaching.

Note: Content Knowledge for Teaching: What Makes It Special? By Ball et al., 2008, retrieved from http://jte.sagepub.com. Date of Copyright by Copyright Holder.

Specifically, we consider mathematics teachers' interests in fractal knowledge of content and students (FKCS), fractal knowledge of content and teaching (FKCT), fractal knowledge of content and curriculum (FKCC), specialized content knowledge of fractals (SCKF), common content knowledge of fractals (CCKF), and horizon content knowledge of fractals (HCKF). The first three types of knowledge belong to pedagogical content knowledge of fractals and the last three types of knowledge belong to subject matter knowledge of fractals. The researchers applied this framework to develop the interest survey, which included eight specific items. Table 1 describes the items 
and their corresponding type of mathematics knowledge for mathematical teaching in fractals.

Table 1

Fractal Knowledge for Mathematical Teaching Needed

\begin{tabular}{lc}
\hline \multicolumn{1}{c}{ Items Developed in the Interest Survey } & FMKT* \\
\hline I would like to know how mathematical curriculum standard & FKCC \\
supports teaching fractal geometry at the secondary school level. & \\
$\begin{array}{l}\text { I would like to know how fractal geometry as a supplementary } \\
\text { material influences the way that students learn and think about }\end{array}$ & FKCS \\
geometry. & \\
I would like to know how fractal geometry supports teaching & SCKF \\
mathematics from very basic concepts to the most advanced & \\
concepts. & \\
$\begin{array}{l}\text { I would like to know how fractal geometry supports learning } \\
\text { across disciplines. }\end{array}$ & HCKF \\
$\begin{array}{l}\text { I would like to know how fractal geometry inspires students' } \\
\text { motivation, interest, and curiosity in teaching and learning }\end{array}$ & \\
mathematics. & \\
$\begin{array}{l}\text { I would like to know how inquiry study/active learning can be } \\
\text { used when integrating fractal geometry for students' math }\end{array}$ & FKCT \\
learning in my class. & \\
$\begin{array}{l}\text { If I had the opportunity to learn fractal geometry in a professional } \\
\text { development program, I would like to participate in the program. }\end{array}$ & CCKF \\
$\begin{array}{l}\text { If I had the knowledge and ability to integrate fractal geometry } \\
\text { into the core curriculum, I would like to integrate fractals in my } \\
\text { curriculum. }\end{array}$ & \\
\hline
\end{tabular}

Note: FMKT refers to fractal knowledge for mathematical teaching.

\section{Methodology}

A quantitative research design was used to address the research question. The research question was investigated using a survey designed by the researchers and examined by a panel of experts and revised according to suggested changes. The survey was conducted after receiving permission from the Institutional Review Board (IRB) of a Southern Institution in the U.S.

\section{Participants}

Participants included male and female 6-12 mathematics teachers who were teaching math courses from grades 6 to 12 in the academic year 20142015 in the United States and China. The researchers anticipated a sample size of approximately 160 respondents according to the result of $g$ power analysis with 8 predictors and an effect size $\mathrm{f}^{2} 0.15$ but received 167 responses from the U.S. and China. Specifically, 82 responses were from the U.S. and 85 responses 
were from China. One response from the U.S. was deleted after data screening. So, the final sample size was 166 . In this study, there were $28.4 \%$ male and $71.6 \%$ female math teachers in the U.S. and $57.6 \%$ male and $42.4 \%$ female math teachers participated in China. Participants were from 3 urban and 5 rural schools of south and central of the U.S. and 4 urban and 5 rural schools of east and south of China. Table 2 describes the information of participants' education background.

Table 2

Frequency Table of Degree

China $(N=85) \quad$ U.S. $(N=81)$

\begin{tabular}{lcccc} 
& Frequency & Percent & Frequency & Percent \\
\hline Bachelor & 56 & $65.9 \%$ & 37 & $45.7 \%$ \\
Master & 21 & $24.7 \%$ & 42 & $51.9 \%$ \\
Specialist & 0 & $0.0 \%$ & 2 & $2.5 \%$ \\
Doctorate & 0 & $0.0 \%$ & 0 & $0.0 \%$ \\
Other types & 8 & $9.4 \%$ & 0 & $0.0 \%$ \\
\hline
\end{tabular}

The years of participants' teaching math are described in Table 3. The highest percentage of the years of teaching math had a range of 11-15 from China $(32.9 \%)$ and a range of $0-5$ from the U.S $(37.0 \%)$.

Table 3

Frequency Table of the Years of Teaching Math

\begin{tabular}{lcccc}
\hline & \multicolumn{2}{c}{ China $(N=85)$} & \multicolumn{2}{c}{ U.S. $(N=81)$} \\
& Frequency & Percent & Frequency & Percent \\
\hline $0-5$ & 11 & $12.9 \%$ & 30 & $37.0 \%$ \\
$6-10$ & 15 & $17.6 \%$ & 16 & $19.8 \%$ \\
$11-15$ & 28 & $32.9 \%$ & 9 & $11.1 \%$ \\
$16-20$ & 16 & $18.8 \%$ & 10 & $12.3 \%$ \\
$21-25$ & 4 & $4.7 \%$ & 6 & $7.4 \%$ \\
26 or above & 11 & $12.9 \%$ & 10 & $12.3 \%$ \\
\hline
\end{tabular}

\section{Instrumentation}

The survey instrument included two parts (see Appendix A). The first part was the participants' common demographic data such as gender, age, degree, the years of teaching math, grade levels, experience of learning fractals, experience of integrating fractals, and nationality. In the survey, mathematics teachers' school location information (item 9 and 10) was not used for data analysis but for the researchers knowing of where data came from.

The second part of the survey instrument was used to examine the level of secondary mathematics teachers' interest in pedagogical content knowledge and subject matter knowledge of fractal geometry. It included eight items. $11=$ "I would like to know how Common Core (National Standard was used to 
replace Common Core in China) supports teaching fractal geometry at the secondary school level." 12 = "I would like to know how fractal geometry as a supplementary material influences the way that students learn and think about geometry." 13 = "I would like to know how fractal geometry supports teaching mathematics from very basic concepts to the most advanced concepts." $14=$ "I would like to know how fractal geometry supports learning across disciplines." $15=$ "I would like to know how fractal geometry inspires students' motivation, interest, and curiosity in teaching and learning mathematics." $16=$ "I would like to know how inquiry study/active learning can be used when integrating fractal geometry for students' learning in my class." 17= "If I had the opportunity to learn fractal geometry in a professional development program, I would like to participate in the program." 18 = "If I had the knowledge and ability to integrate fractal geometry into the core curriculum, I would like to integrate fractals in my curriculum." Participants were asked to rate their level of interest in fractal geometry on a scale of 1-4: 1 = completely disagree, 2 = somewhat disagree, 3 = somewhat agree, and $4=$ completely agree. The reliability test was conducted for examining the level of internal consistency for the four levels' scales with the sample of 166 . The Cronbach's alpha was 0.94, which indicated a high level of internal consistency for the scales used in this instrument. The average of a total of eight item scores was used as the score of the dependent "interest" when running multiple linear regressions.

\section{Procedure}

Upon approval from the Southern Institution's IRB, the English version of the survey was used for U.S. secondary mathematics teachers; the Chinese version of the survey was used for Chinese secondary mathematics teachers. Three recruitment ways were used to distribute the surveys and tests: electronic copies, online versions (on Quatrics.com), and hard copies. Data was reported anonymously so that readers cannot identify any teacher or associate that teacher with any specific response. The teachers needed approximately fifteen minutes to complete the survey. The participants' responses from the survey instrument were entered to SPSS version 22 by the researchers. The researchers conducted data screening and analyzed the hypothesis by conducting a multiple linear regression test.

\section{Data analysis}

A standard multiple regression model was selected for this study to know the effect of each predictor in the criterion. Linear Regression with SPSS was conducted to run the standard regression analysis. To run the multiple regression, "Recode" with SPSS was used to transfer categorical variables into dichotomies. According to Meyers, Gamst, and Guarino (2006), the reference group should have a relatively large sample size. For example, according to frequencies of analyses, the group of China should be the reference group of nationality. After recoding into different names, the new independent variables 
were: U.S. (renamed from nation), male (renamed from gender), age 20-25, age 26-30, age 36-40, age 41-45, age above 45, M.S. degree (renamed from degree), years6-10, years11-15, years 16-20, years21-25, years above 25, high levels (renamed from grade levels), LearnedFra (renamed from experience of learning fractals), and IntegratedFra (renamed from experience of integrating fractals).

\section{Results}

Both U.S. and Chinese secondary mathematics teachers showed moderate level of interest in gaining pedagogical content knowledge and subject matter knowledge of fractals based on their average score of interest $\left(M_{\text {Chinese }}=2.42, M_{u . s .}=2.88\right)$ according to the 4-point scale (see Table 4). The statistics standard deviations of both are very close.

\section{Table 4}

Descriptive Statistics of the Dependent Variable (Interest)

\begin{tabular}{lcccc}
\hline & \multicolumn{2}{c}{ China $(N=85)$} & \multicolumn{2}{c}{ U.S. $(N=81)$} \\
& $M$ & $S D$ & $M$ & $S D$ \\
\hline Interest & 2.42 & 0.72 & 2.88 & 0.76 \\
\hline
\end{tabular}

From Table 5, U.S. teachers scored higher averages in each item than Chinese teachers. The U.S. groups ranked the highest average level on Item 14 "I would like to know how fractal geometry supports learning across disciplines" $(M=3.02, S D=0.87$, mode $=3)$. The second place was Item 13 "I would like to know how fractal geometry supports teaching mathematics from very basic concepts to the most advanced concepts" $(M=2.96, S D=0.90$, mode $=3)$, while Items 13 and 14 were ranked as the last two places in the Chinese group. The Chinese group ranked the highest average level on Item 17 "If I had the knowledge and ability to integrate fractal geometry in a professional program, I would like to participate in the program" $(M=2.75, S D=0.87$, mode $=3)$. The second place was Item 18 "If I had the knowledge and ability to integrate fractal geometry into the core curriculum, I would like to integrate fractals in my curriculum" ( $M=2.60, S D=0.90$, mode $=3)$, while Items 17 and 18 were ranked as the last two places in the U.S. group. Despite this, the average level of scores on Items 17 and 18 in the Chinese group were still lower than in the U.S. group. Hence, U.S. secondary mathematics teachers showed more interests in gaining horizon content knowledge and specialized content knowledge of fractals, while Chinese secondary teachers showed more interests in common content knowledge of fractals and fractal knowledge of content curriculum. From the statistics of means and modes, we could draw a conclusion: the participants in both countries showed that they were somewhat willing to learn fractals and integrate fractals into their curriculum, and U.S. participants had stronger willingness on each item than Chinese participants. 
Table 5

Descriptive Statistics of Interest in Fractal Geometry

\begin{tabular}{lcccccc}
\hline \multirow{2}{*}{ Items } & \multicolumn{3}{c}{ China $(\mathrm{N}=85)$} & \multicolumn{3}{c}{ U.S. (N=81) } \\
& Mode $^{b}$ & Mean & SD & Mode $^{b}$ & Mean & $S D$ \\
\hline 11 & 2 & 2.26 & 0.92 & 3 & 2.82 & 0.91 \\
12 & 2 & 2.32 & 0.80 & 3 & 2.91 & 0.84 \\
13 & 2 & 2.14 & 0.97 & 3 & 2.96 & 0.90 \\
14 & 2 & 2.25 & 0.82 & 3 & 3.02 & 0.87 \\
15 & 3 & 2.52 & 0.96 & 3 & 2.86 & 0.89 \\
16 & 3 & 2.54 & 0.92 & 3 & 2.81 & 0.82 \\
17 & 3 & 2.75 & 0.87 & 3 & 2.81 & 0.96 \\
18 & 3 & 2.60 & 0.90 & 3 & 2.78 & 0.88 \\
\hline
\end{tabular}

Note: The interest scores were based on a 4-point scale, where $1=$ "completely disagree," 2 = "somewhat disagree," 3 = "somewhat agree," 4 = "completely agree."

The multiple linear regression model as a whole had statistically significant predictive capability in this study. This conclusion came from the statistical $\mathrm{F}$ values with its $\mathrm{p}$ values from the summary of model Table $6 . F$ (16, $149)=3.00, p<0.01$. The combination of the selected independent variables explained $24 \%$ of the variance of dependent variable interest.

Table 6

ANOVA Summary Table of the Standard Multiple Regression (DV = Interest)

\begin{tabular}{lcccccc}
\hline Source & $\mathrm{SS}$ & $\mathrm{df}$ & $\mathrm{MS}$ & $\mathrm{F}$ & $\mathrm{p}$ & $\mathrm{R}^{2}$ \\
\hline Regression & 24.01 & 16 & 1.50 & 3.00 & $0.01^{*}$ & 0.24 \\
Residual & 74.60 & 149 & 0.50 & & & \\
Total & 98.62 & 165 & & & & \\
\hline
\end{tabular}

Note: * Refers to less than 0.01

However, not all predictors had statistically unique significant relationships with the dependent variables from the $t$ and $p$ (critical value 0.05 ) values of Table 7 . The $t$ and $p$ values in Table 7 showed that the variables, male, age 20-25, age 26-30, age 41-45, age above 45, M.S. degree, years 6-10, years 11-15, years 16-20, years 21-25, years above 25, high levels, and LearnedFra statistically had no significant relationship with the criterion. The variables, U.S. $(t=2.54, p=0.01)$, age 36-40 $(t=2.22, p=0.03)$ and IntegratedFra $(t=2.31$, $p=0.02)$ had statistically significant relationships with the criterion.

Further, the values of the Pearson correlations showed that the variables age 41-45 and age 20-25 $(r=0.01)$ had the least positive correlation with the criterion. The independent variable "U.S." $(r=0.29)$ had the most positive correlation with the criterion, the independent variable "M.S. degree" $(r=0.21)$ had the second most positive correlations with the criterion, and it was followed by the independent variable "LearnedFra" $(r=0.18)$ and "IntegratedFra" 
$(r=0.16)$. The order of the structure coefficients in Table 7 showed that "U.S." (structure coefficient $=0.61$ ) was the strongest reflection of the construct underlying the variate; the variable "master degree" ( structure coefficient $=0.42$ ) had the rank of second place; the variable "LearnedFra" (structure coefficient = 0.37 ) was at the third place.

Table 7

\begin{tabular}{|c|c|c|c|c|c|c|c|}
\hline Variable & $b$ & beta & $r$ & $S r^{2}$ & $\begin{array}{l}\text { Structure } \\
\text { coefficient }\end{array}$ & $t$ & $p$ \\
\hline U.S. & 0.35 & .23 & .29 & .03 & .61 & 2.54 & .01 \\
\hline Male & .02 & .02 & -.09 & $.01 *$ & -.19 & .19 & .85 \\
\hline Age $20-25$ & -.10 & -.04 & .01 & $.01 *$ & .02 & -.37 & .72 \\
\hline Age $26-30$ & -.12 & -.05 & -.02 & $.01 *$ & -.05 & -.57 & .57 \\
\hline Age $36-40$ & .44 & .22 & .07 & .03 & .15 & 2.22 & .03 \\
\hline Age $41-45$ & .19 & .09 & .01 & $.01 *$ & .02 & .80 & .42 \\
\hline Age above 45 & .38 & .20 & .14 & .01 & .28 & 1.44 & .15 \\
\hline M.S. degree & .20 & .13 & .21 & .01 & .42 & 1.62 & .11 \\
\hline Years 6-10 & .09 & .05 & .07 & $.01 *$ & .15 & .42 & .68 \\
\hline Years 11-15 & -.47 & -.26 & -.26 & .02 & -.53 & -1.96 & .05 \\
\hline Years 16-20 & -.07 & -.03 & .12 & $.01 *$ & .13 & -.23 & .82 \\
\hline Years 21-25 & -.16 & -.05 & .05 & $.01 *$ & .11 & -.45 & .66 \\
\hline Years above $^{b}$ & -.36 & -.16 & .04 & .01 & .08 & -1.04 & .30 \\
\hline High levels & -.08 & -.05 & .07 & $.01 *$ & .14 & -.61 & .54 \\
\hline LearnedFra & .20 & .13 & .18 & .01 & .37 & 1.50 & .14 \\
\hline IntegratedFra & .37 & .20 & .16 & .03 & .31 & 2.31 & .02 \\
\hline Constant & 2.27 & & & & & & \\
\hline
\end{tabular}

Note: $\mathrm{Sr}^{2}$ refers to squared semi-partial correlation; ${ }^{\mathrm{b}}$ refers to the years of teaching above 25 ;

* refers to less than 0.01 .

The squared semipartial correlation indexes (see Table 7) were calculated by squaring the index of part correlation in the output of Coefficients table that described the variance uniquely accounted by each predictor in the full model. The top four of the predictors' unique contributions to the prediction model from the largest to smallest was "U.S." $\left(\mathrm{Sr}^{2}=0.03\right)$, "IntegratedFra" $\left(\mathrm{Sr}^{2}\right.$ $=0.03)$, "age36-40" $\left(S r^{2}=0.03\right)$, and "years 11-15" $\left(S r^{2}=0.02\right)$. The hypothesis was: the factors degree, grade levels, experience of learning fractals, and experience of integrating fractals will account for more variance than gender, age, the years of teaching math, and nationality in the overall mean interest in integrating fractal geometry in the math core curriculum. The actual statistics results indicated that the factors nationality, experience of integrating fractals, age, and the years of teaching math accounted for more variance than degree, experience of learning fractals, grade levels, and gender in the overall mean interest survey scores. The regression equation is below. 
Interested $($ predicted $)=2.27+(0.35)($ U.S. $)+(0.02)($ Male $)-(0.10)($ age $20-25)-(0.12)($ age $26-30)+(0.44)($ age $36-40)+(0.19)($ age $41-45)+(0.38)$ (age above 45$)+(0.20)($ M.S. degree $)+(0.09)($ years 6-10) $-(0.47)$ (years 11$15)-(0.07)($ years $16-20)-(0.16)($ years $21-25)-(0.36)($ years above 25$)-$ (0.08) (high levels) + (0.20) (Learned Fra) + (0.37) (IntegratedFra)

This equation explains all the details of each factor's accountability of variance in this model. For example, the b weight (0.35) of U.S. variable in the equation can be interpreted as followings: when controlling the other predictors, the group of U.S. mathematics teachers scored interest on average 0.35 times greater than the group of Chinese mathematics teachers. If the $b$ weight is negative, then the words "greater than" in the above sentence should be replaced with "less than".

\section{Discussion}

In this study, mathematics teachers showed a moderate level of interest in learning and integrating fractals in their classroom because the average level of interest for each item was about 2.5 in both U.S. and Chinese groups. The interest levels in eight items showed quite distinct ranks between two countries. U.S. mathematics teachers expressed strong inclination in developing their horizon content knowledge and specialized content knowledge of fractals. Chinese teachers seemed more willing to gain common content knowledge and knowledge of content and curriculum about fractals. The different inclinations of professional learning in fractals showed in two countries may reflect on their different educational background and career experiences. The curriculum designers of professional program for in-services mathematics teachers may consider how to meet their needs and interests according to the rank of each item to improve their corresponding knowledge and abilities in dealing with teaching fractals.

The nationality variable made significant difference regarding interest level in this study. U.S. mathematics teachers showed a higher level of interest in fractals than Chinese teachers, specifically in both pedagogical content knowledge and subject matter knowledge. Teachers between the ages of 36 and 40 showed the greatest interest in fractal geometry out of all age groups. Teachers who have had the experience of integrating fractals into their class showed higher interest in gaining knowledge of teaching mathematics. Thus, nationality, age, and the experience of integrating fractals did significantly impact their interests in fractals. The hypothesis was not fully supported. The factors nationality, experience of integrating fractals, age, and the years of teaching math accounted for more variance than degree, experience of learning fractals, grade levels, and gender in the overall mean interest survey scores.

U.S. math teachers had a higher average score of each interest item than Chinese math teachers in this study. As Chinese mathematics education researchers, we need to think about the reason behind the phenomenon. We 
know both countries' education systems are different, especially in the evaluation of teachers' performance. In the U.S., students' ACT or SAT scores are not tied with teacher performance appraisal. In this environment, mathematics teachers have less stress for integrating fractal content into their class even when the fractal content is not required to be tested. In China, students' performance on entrance exam to college is the key element used for evaluating teachers' teaching performance by principals in schools. In this case, most math teachers just want to focus on the content required in the entrance exam. Anything else would be considered a waste of time. In other words, if the content is required in the national entrance exam, then it matters for teachers' teaching. Currently, fractal geometry is not the compulsory content required in Chinese mathematics curriculum, so mathematics teachers would not put their efforts into this topic. Although some fractal topics have been addressed in the Chinese national curriculum as optional studies, most teachers choose to ignore it because it is optional, not demanded. The phenomenon that Chinese teachers teach for test and students learn for test is common (Ying, 2006). This is a troublesome phenomenon that math teachers only want to teach tested contents in China. If math teachers do not have the open minds to embrace modern mathematics, we cannot expect our students to do so either. Ying (2006) pointed out that we should stop the phenomenon of teaching and learning for test soon.

Math teachers who had experience in integrating or learning fractals showed more interest in fractals than math teachers who did not have in this study. It may indicate that the experience of learning and integrating fractals makes math teachers more intrigued by its value. This phenomenon has been addressed in Mandelbrot and Frame (2002). We should encourage and support teachers to integrate fractal geometry in their class to open students' eyes on geometry and change the view and way of thinking about geometry. Such experience will benefit both teachers' teaching and students' learning (Mandelbrot \& Frame 2002; Peitgen \& Richter, 1986). The group of teachers who have had master's degrees showed more interest in fractals than those who have had bachelor's degrees. This indicates that teachers who have higher degrees are more eager to gain new information to improve selves in teaching mathematics. Zhang (2015) provided evidence to support this phenomenon. This may also indicate that they have more confidence in challenging their learning in fractals. Teacher educators can think about starting with recruiting higher degree teachers to participate in professional program about fractals and gradually draw more math teachers' attention. Compared with others, teachers whose ages are between 36 and 40 showed the greatest interest in fractal geometry. This would provide reference for teacher educators to consider what age group would be more likely targeted as participants when they offer professional programs about fractals. Although the sample of 166 participants is tested by G-power analysis and the result proved solidity, limitations still exist because of a relatively small data set. Future study should be focused on investigating the effectiveness of professional development about fractal 
knowledge and its related pedagogical content knowledge and subject matter knowledge in both U.S. and China.

\section{References}

Adams, H. M., \& Russ. J. C. (1992). Chaos in the classroom: Exposing gifted elementary school children to chaos and fractals. Journal of Science and Education and Technology, 1, 191 -209.

Ball, D. L., Thames, M. H., \& Phelps, G. (2008). Content knowledge for teaching: What makes it special? Journal of Teacher Education, 59(5), 389-407.

Barry, A. (2013). Content integration through the eyes of novice and experienced teachers. Teacher Education Quarterly, 40(3), 93-106.

Retrieved from

http://www.jstor.org.ezproxy.library.yorku.ca/stable/43684704

Barton, P. S. (2003). Pascal's triangle. Montessori Life, 1, 35-36.

China Mathematics Curriculum Standards (10-12). (2003). Retrieved from http://hrd.apec.org/images/2/29/54.3.pdf.

Common Core State Standards for Mathematics (CCSSM). (2015). Retrieved from http://www.corestandards.org/Math/.

Davis, B., \& Sumara, D. J. (2000). Curriculum forms: On the assumed shapes of knowing and knowledge. Curriculum Studies, 32, 821-845.

Ding, J., \& Li, Z. (2009). On the dimension of sierpiński pedal triangles. Fractals, 17, 39-43.

England Mathematics Curriculum Standards. (2014). Retrieved from http://www.moe.gov.sg/education/syllabuses/sciences/files/mathssecondary.pdf.

Fraboni, M., \& Moller, T. (2008). Fractals in the classroom. Mathematics Teachers, 102 (3), 197-199.

Frame, M., \& Mandlebrot, B. B. (2002). Fractals, graphics, and mathematics education. Washington, DC: The Mathematics Association of American.

Gluchoff, A. (2006). Hands-on fractals and the unexpected in mathematics. NCTM: The Mathematics Teacher, 99, 570-575.

Habecker, B., \& Crannell, A. (2004). Using fractals to motivate linear algebra. UMAP Journal, 25, 51-82.

ICMI. (1995). Perspectives on the teaching of geometry for the $21^{\text {st }}$ century. Educational Studies in Mathematics, 28, 91-98.

Jarry-Shore, M. (2013). An exploration of per cents and fractions through a study of fractals. Delta- $k, 50,34-38$.

Korea Mathematics Curriculum Standards. (n.d.). Retrieved from http://hrd.apec.org/images/2/2c/54.5.pdf.

McHugh, K. (2006). Fractals and nature: It is elementary. Retrieved from: http:/www.chatham.edu/pti/curriculum/units/2006/McHugh.pdf.

Padula, J. (2005). Fractal music: The mathematics behind 'techno' music. The 
Australian Mathematics Teach, 47, 4-8.

Padula, J. (2009). More about how to teach fractal geometry with music. The Australian Mathematics Teach, 65, 37-40.

Peitgen, H. O., \& Richter, P. H. (1986). The beauty of fractals. Berlin, Germany: Springer-Verlag.

Singer, F. M., \& Voica, C. (2013). A problem-solving conceptual framework and its Implications in designing problem-posing tasks. Educational Studies in Mathematics, 83, (1), 9-26. Retrieved from http://www.jstor.org.ezproxy.library.yorku.ca/stable/23434193.

Vacc, N. N. (1999). Exploring fractals geometry with children. School Science and Mathematics, 2, 77-83.

Ying, X. (2006). "Examination-oriented education theory" should be stopped. Global Education, 229 (9), 23-29. [In Chinese]

Zhang, Z. (2015). The analysis of professional development features of school teachers with M.S degrees. Shanghai Jiaoyu Keyan, 10, 53-57. [In Chinese]

\section{Appendix A}

\section{The Survey of Fractal Interest}

The following survey is designed to measure your interest in fractal geometry that you have had in your previous learning or teaching experience. Interest as it relates to this survey is the certainty that you would like to do something (items 11-18). Demographics are asked in items 1-10 to investigate the relationship between teachers' background and the interest in fractal geometry.

This questionnaire should take between 5-10 minutes. Your participation is completely voluntary, and you may discontinue participation without penalty or prejudice against you. You may choose not to answer any questions that make you uncomfortable. By completing this survey, you are choosing to participate in the study. This project has been reviewed by the Human Subjects Protection Review Committee, which ensures that research projects involving human subjects follow federal regulations.

Please answer the following questions to the best of your ability. Your responses to this survey will remain anonymous.

1) Please select your gender.
a.) Male
b.) Female

2) Please select your age range.
a.) $20-25$
b.) $26-30$
c.) $31-35$
d.) $36-40$
e.) $41-45$
f.) 46 or above

3) Please select the highest degree you have obtained.
a.) Bachelor degree
b.) Master degree
c.) Specialist degree 

d.) Doctoral degree
e.) Other types:

5) Please select the current grade that you are teaching math.
a.) $6^{\text {th }}$ grade
b.) $7^{\text {th }}$ grade
c.) $8^{\text {th }}$ grade
d.) $9^{\text {th }}$ grade
e.)
$10^{\text {th }}$ grade
f.) $11^{\text {th }}$ grade
g.) $12^{\text {th }}$ grade

6) Have you ever taught geometry in any of your math courses?
a.) Yes
b.) No

7) Have you ever learned fractals in your educational experience?
a.) Yes
b.) No

8) Have you ever integrated fractal geometry in your math curriculum?
a.) Yes
b.) No

9) Do you teach in a rural, suburban, and city school?
a.) Rural
b.) Suburban
c.) City

10) In what state do you teach?

Please answer the following questions to the best of your ability after you read the short paragraph below.

The research has demonstrated that fractal geometry connects many mathematics concepts and theorems in the secondary math core curriculum and to other subject areas. It can be well used for the applications of algebra and traditional geometry in secondary mathematics learning, and it can also be used for motivating students to conduct inquiry study/active learning, inspiring students to discover novelty, and increasing interest in learning.

For items 11-18, please rate your level of interest on a scale of 1-4.

$$
\begin{aligned}
& 1=\text { completely disagree } \\
& 2=\text { somewhat disagree } \\
& 3=\text { somewhat agree } \\
& 4=\text { completely agree }
\end{aligned}
$$

11) I would like to know how Common Core supports teaching fractal geometry at the secondary school level.
1
2
3
4

12) I would like to know how fractal geometry as a supplementary material influences the way that students learn and think about geometry.
1
2
3
4

13) I would like to know how fractal geometry supports teaching mathematics from very basic concepts to the most advanced concepts.

1 
14) I would like to know how fractal geometry supports learning across disciplines. $\begin{array}{llll}1 & 2 & 3 & 4\end{array}$

15) I would like to know how fractal geometry inspires students' motivation, interest, and curiosity in teaching and learning mathematics.
1
2
3
4

16) I would like to know how inquiry study/active learning can be used when integrating fractal geometry for students' math learning in my class.
1
2
3
4

17) If I had the opportunity to learn fractal geometry in a professional development program, I would like to participate in the program.

$\begin{array}{llll}1 & 2 & 3 & 4\end{array}$

18) If I had the knowledge and ability to integrate fractal geometry into the core curriculum, I would like to integrate fractals in my curriculum.

1

2

3

4

\section{Corresponding Author:}

Suanrong Chen

Yangzhou University

Email:lazichen@163.com 